\title{
A Stability Indicating UPLC Method for the Determination of Tramadol Hydrochloride: Application to Pharmaceutical Analysis
}

\author{
Kanakapura B. Vinay, Hosakere D. Revanasiddappa, Cijo M. Xavier, \\ Pavagada J. Ramesh, and Madihalli S. Raghu \\ Department of Chemistry, University of Mysore, Manasagangothri, Karnataka, Mysore 570 006, India \\ Correspondence should be addressed to Hosakere D. Revanasiddappa, hdrevanasiddappa@yahoo.com
}

Received 28 February 2012; Accepted 28 March 2012

Academic Editor: Antonio Martín-Esteban

Copyright ( $) 2012$ Kanakapura B. Vinay et al. This is an open access article distributed under the Creative Commons Attribution License, which permits unrestricted use, distribution, and reproduction in any medium, provided the original work is properly cited.

\begin{abstract}
The use of Ultra Performance Liquid Chromatography (UPLC), with a rapid 5-minute reversed phase isocratic separation on a $1.7 \mu \mathrm{m}$ reversed-phase packing material to provide rapid "high throughput" support for tramadol hydrochloride (TMH) is demonstrated. A simple, precise and accurate stability-indicating isocratic UPLC method was developed for the determination of TMH in bulk drug and in its tablets. The method was developed using Waters Aquity BEH C18 column $(100 \mathrm{~mm} \times 2.1 \mathrm{~mm}$, $1.7 \mu \mathrm{m}$ ) with mobile phase consisting of a mixture of potassium dihydrogen phosphate buffer of $\mathrm{pH} 2.8$ and an equal volume of acetonitrile $(60: 40 \mathrm{v} / \mathrm{v})$. The eluted compound was detected at $226 \mathrm{~nm}$ with a UV detector. The standard curve of mean peak area versus concentration showed an excellent linearity over a concentration range $0.5-300 \mu \mathrm{g} \mathrm{mL}^{-1} \mathrm{TMH}$ with regression coefficient $(r)$ value of 0.9999 . The limit of detection $(\mathrm{S} / \mathrm{N}=3)$ was $0.08 \mu \mathrm{g} \mathrm{mL}^{-1}$ and the limit of quantification $(\mathrm{S} / \mathrm{N}=10)$ was $0.2 \mu \mathrm{g} \mathrm{mL}$. Forced degradation of the bulk sample was conducted an accordance with the ICH guidelines. Acidic, basic, hydrolytic, oxidative, thermal and photolytic degradation were used to assess the stability indicating power of the method. TMH was found to degrade significantly in acidic, basic and oxidative stress conditions and stable in thermal, hydrolytic and photolytic conditions.
\end{abstract}

\section{Introduction}

Tramadol hydrochloride (TMH), chemically known as (1R,2R)-rel-2-[(dimethylamino)methyl]-1-(3-methoxyphenyl)cyclohexanol (Figure 1), is a synthetic analogue of codeine and is a centrally acting analgesic agent [1]. It is metabolized by the cytochrome P450 enzyme system in the liver to form eleven metabolites of which odesmethyltramadol (M1) predominates and has analgesic properties [2]. It has been used since 1977 for the relief of severe physical pain and has been the most widely sold opioid analgesic drug in the world [3]. TMH is official in European Pharmacopeia (EP) [4] which describe nonaqueous titration with perchloric acid as titrant the end point being located potentiometrically. Ultraviolet spectrophotometry $[5,6]$, high-performance liquid chromatography [6-9], thin layer chromatography-densitometry [10], capillary isotachophoresis [11], flow injection chemiluminescence spectrometry [12], voltametry [13-15], ion-selective-based potentiometry [16-22], visible spectrophotometry [23$28]$, and titrimetry $[26,29]$ for determining TMH in pharmaceutical dosage forms.

In addition, there have been reports of its assay when present in combination with other drugs. TDH and ibuprofen were assayed simultaneously by first-order derivative spectrophotometry and HPLC with UV-detection [30]. TMH along with dexketoprofen and haloperidol have been determined by HPLC-diode array detection (DAD) method [31]. Simultaneous analysis of TMH and aceclofenac in a commercial tablet was accomplished also by HPLC with UV-detection method [32]. Simultaneous determination of paracetamol, TMH, and domperidone in combined dosage 


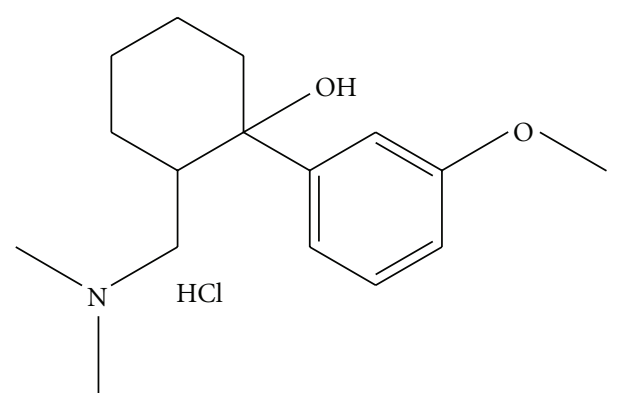

FIGURE 1

form using RP-HPLC has been reported by Karunakaran et al. [33].

In recent years, there has been an increased tendency towards development of stability-indicating analysis [3437], using the approach to stress testing enshrined in International Conference on Harmonisation (ICH) guideline Q2A(R2) [38]. This approach is being extended to pharmaceuticals to enable accurate and precise quantification of drugs in the presence of their degradation products. Though there are many reported methods for the analysis of TMH either alone [5-29] or in combination with other drugs [3032] in pharmaceutical dosage forms, the literature on the stability-indicating methods is scarce. Mohammadi et al. [39] have evaluated the stability of tramadol enantiomers using a chiral stability-indicating capillary electrophoresis method and its application to pharmaceutical analysis. Chemical stability of TMH in injection has been reported by Gupta [40].

Ultraperformance liquid chromatography (UPLC) is a relatively new technique giving new possibilities in liquid chromatography, especially concerning decrease of time and solvent consumption [41]. UPLC system is designed in a special way to withstand high system backpressure. Special analytical columns UPLC Acquity UPLC BEH $\mathrm{C}_{18}$ packed with $1.7 \mu \mathrm{m}$ particles are used in the system. The UPLC system allows shortening analysis time upto nine times compared to the conventional HPLC system, but separation efficiency remains the same or is even improved. As efficiency and speed of analysis are of great importance in many applications of liquid chromatography, especially in pharmaceutical, toxicological, and chemical analysis, where it is important to increase throughput and reduce analysis costs, UPLC could play a significant role in the future of liquid chromatography.

Three reports are found in the literature dealing with the application of UPLC with mass spectrometric detection for the determination of TMH in different matrices. A sensitive UPLC-MS/MS method for TMH in urine and whole blood in forensic context has very recently been reported [42]. Kasprzyk-Hordern et al. [43] determined TMH in surface water by solid-phase extraction and UPLC-positive electrospray ionization tandem mass spectrometry. Simultaneous screening and quantification of 29 drugs of abuse including TMH in oral fluid [44] has been reported by Badawi et al. Solid phase extraction and UPLC-MS/MS
TABLE 1: Linearity and regression parameters with precision data.

\begin{tabular}{lc}
\hline Parameter & Value \\
\hline Linear range, $\mu \mathrm{g} \mathrm{mL}^{-1}$ & $0.5-300$ \\
Limits of quantification, (LOQ), $\mu \mathrm{g} \mathrm{mL}^{-1}$ & 0.2 \\
Limits of detection, (LOD), $\mu \mathrm{g} \mathrm{mL} \mathrm{mL}^{-1}$ & 0.08 \\
Regression equation & \\
$\quad$ Slope $(b)$ & 30620.1 \\
Intercept $(a)$ & 19330.0 \\
Correlation coefficient $(r)$ & 0.9999 \\
Standard deviation of $b,\left(S_{b}\right)$ & 76.0 \\
Standard deviation of $a,\left(S_{a}\right)$ & 13694.5 \\
\hline
\end{tabular}

by Liquid chromatography-positive electrospray ionization tandem mass spectrometry has recently [45] been used for the multiresidue analysis of drugs of abuse in waste water and surface water.

Though a number of liquid chromatographic methods have earlier proposed for TMH $[5-8,29-31]$ no attempt has been made to apply this new type of LC (UPLC) for pharmaceuticals except in body fluids, oral fluids, and surface and waste waters [42-45] despite its many fold advantages.

The aim of this work was to develop a rapid, precise, accurate, and validated stability-indicating UPLC method for the determination of tramadol $\mathrm{HCl}$ in bulk and tablets. This was accomplished with a Waters Acquity UPLC system and Acquity BEH column $(\mathrm{C} 18,100 \mathrm{~mm}, 2.1 \mathrm{~mm}$, and $1.7 \mu \mathrm{m})$. The stability indicating power of the method was established by comparing the chromatograms obtained under optimized conditions before forced degradation with those after degradation via acidic, basic, hydrolytic, oxidative, thermal, and photolytic stress conditions.

\section{Experimental}

2.1. Materials and Reagents. Pharmaceutical grade TMH was kindly supplied by Jubilant Life Sciences Limited, Mysore, India, as gift and used as received. Commercial dosage forms used: Nobligan 50 and Meridol 50 tablets were purchased from local commercial sources. HPLC grade acetonitrile was purchased from Merck India. Pvt. Ltd., Mumbai, India, doubly distilled water was used throughout the investigation.

2.2. Chromatographic Conditions and Equipments. Chromatography was performed on a Waters Acquity UPLC system (Waters, Manchester, UK) using an Acquity BEH column (C-18 $100 \mathrm{~mm}, 2.1 \mathrm{~mm}$, and $1.7 \mu \mathrm{m}$; Waters, Manchester, UK) equipped with binary solvent delivery pump, autosampler and tunable UV (TUV) detector. The column oven temperature was maintained at $35^{\circ} \mathrm{C}$ and the autosampler temperature maintained at ambient. Isocratic mobile phase flow was carried out throughout the run. Total cycle time was $5 \mathrm{~min}$ with a flow rate of $0.5 \mathrm{~mL}^{-1} \mathrm{~min}$ and an injection volume of $4 \mu \mathrm{L}$ using partial loop mode. The output signal was monitored and processed using Empower2 software. 


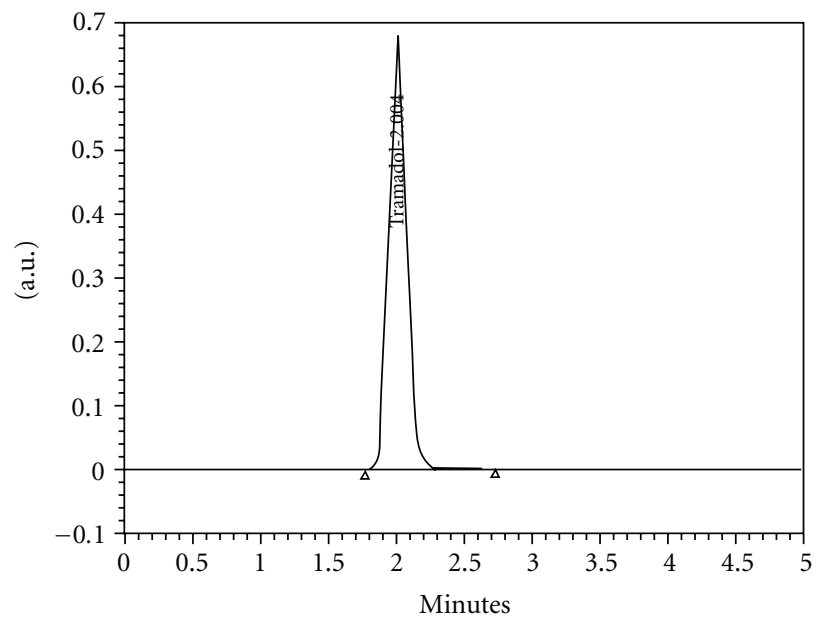

(a)

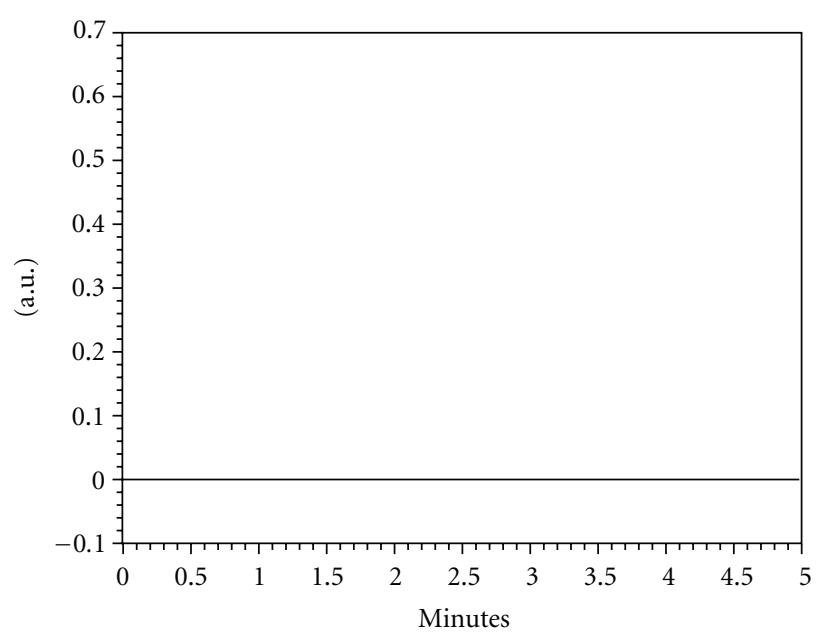

(b)

Figure 2: (a) Typical chromatogram of TMH $\left(200 \mu \mathrm{g} \mathrm{m}^{-1}\right)$, (b) (Blank).

TABLE 2: Results of accuracy study $(n=5)$.

\begin{tabular}{|c|c|c|c|c|}
\hline \multirow{2}{*}{$\begin{array}{l}\text { Concentration of TMH } \\
\text { injected, } \mu \mathrm{g} \mathrm{mL}-1\end{array}$} & \multicolumn{2}{|c|}{ Intraday } & \multicolumn{2}{|c|}{ Interday } \\
\hline & $\begin{array}{l}\text { Concentration of TMH } \\
\text { found, } \mu \mathrm{g} \mathrm{mL}^{-1}\end{array}$ & $\mathrm{RE}, \%$ & $\begin{array}{l}\text { Concentration of TMH } \\
\text { found, } \mu \mathrm{g} \mathrm{mL} \mathrm{m}^{-1}\end{array}$ & RE, \% \\
\hline 150 & 150.80 & 0.54 & 151.03 & 0.69 \\
\hline 200 & 199.48 & 0.26 & 198.24 & 0.88 \\
\hline 250 & 249.16 & 0.34 & 252.12 & 0.85 \\
\hline
\end{tabular}

TABle 3: Results of precision study $(n=5)$.

\begin{tabular}{lcccccc}
\hline $\begin{array}{l}\text { Concentration } \\
\text { injected, } \mu \mathrm{g} \mathrm{mL}^{-1}\end{array}$ & Mean area $\pm \mathrm{SD}$ & $\begin{array}{c}\text { Intraday precision } \\
\text { \%RSD }\end{array}$ & \%RSD & Mean area \pm SD & Interday precision \\
\%RSD $^{\mathrm{a}}$ & \%RSD $^{\mathrm{b}}$ \\
\hline 150 & $4640550 \pm 9012$ & 0.19 & 0.28 & $4621200 \pm 18068$ & 0.39 & 0.23 \\
200 & $6136915 \pm 10694$ & 0.17 & 0.13 & $6124962 \pm 49690$ & 0.81 & 0.19 \\
250 & $7657557 \pm 20715$ & 0.35 & 0.27 & $7719500 \pm 40184$ & 0.52 & 0.78 \\
\hline
\end{tabular}

${ }^{a}$ Relative standard deviation based on peak area.

${ }^{b}$ Relative standard deviation based on retention time.

TABLE 4: Method robustness.

\begin{tabular}{|c|c|c|c|c|c|c|c|c|c|}
\hline Condition & Modification & $\begin{array}{c}\text { Mean Peak area } \pm \\
\text { SD }^{*}\end{array}$ & $\%$ RSD & $\begin{array}{c}\text { Mean Rt } \pm \\
\text { SD }^{*}\end{array}$ & $\% \mathrm{RSD}$ & $\begin{array}{c}\text { Mean } \\
\text { theoretical } \\
\text { plates } \pm \mathrm{SD}^{*}\end{array}$ & $\%$ RSD & $\begin{array}{l}\text { Mean tailing } \\
\text { factor } \pm \mathrm{SD}^{*}\end{array}$ & $\%$ RSD \\
\hline \multirow{3}{*}{ Temperature } & $35^{\circ} \mathrm{C}$ & $6207527 \pm 6506$ & 0.10 & $2.015 \pm 0.006$ & 0.30 & $3467 \pm 59.65$ & 72 & $1.10 \pm 0.02$ & 0.18 \\
\hline & $40^{\circ} \mathrm{C}$ & $6136916 \pm 10695$ & 0.17 & $2.007 \pm 0.007$ & 0.33 & $3953 \pm 85.36$ & 16 & $1.01 \pm 0.01$ & 0.10 \\
\hline & $45^{\circ} \mathrm{C}$ & $6186601 \pm 6723$ & 0.11 & $1.99 \pm 0.006$ & 0.30 & $3998 \pm 56.56$ & 41 & $1.11 \pm 0.02$ & 0.18 \\
\hline \multirow{3}{*}{$\begin{array}{l}\text { Mobile phase } \\
\text { composition }\end{array}$} & $40: 60$ & $6134526 \pm 10115$ & 0.16 & $1.9 \pm 0.006$ & 0.30 & $4021 \pm 10536$ & 62 & $1.02 \pm 0.05$ & 0.49 \\
\hline & $50: 50$ & $6188507 \pm 9437$ & 0.15 & $2.0 \pm 0.006$ & 0.30 & $4068 \pm 70.56$ & 73 & $1.01 \pm 0.04$ & 0.40 \\
\hline & $60: 40$ & $6345681 \pm 9986$ & 0.16 & $1.99 \pm 0.08$ & 0.40 & $4098 \pm 86.97$ & 12 & $0.98 \pm 0.05$ & 0.51 \\
\hline \multirow{3}{*}{ Flow rate } & 0.35 & $7107242 \pm 8520$ & 0.12 & $2.01 \pm 0.05$ & 0.25 & $3987 \pm 101.16$ & 53 & $1.02 \pm 0.02$ & 0.20 \\
\hline & 0.40 & $6112464 \pm 8817$ & 0.14 & $2.006 \pm 004$ & 0.20 & $4016 \pm 88.84$ & 19 & $1.02 \pm 0.03$ & 0.29 \\
\hline & 0.45 & $5455471 \pm 9053$ & 0.17 & $1.99 \pm 0.05$ & 0.25 & $3987 \pm 101.16$ & 53 & $1.02 \pm 0.02$ & 0.20 \\
\hline \multirow{3}{*}{ Wavelength } & $224 \mathrm{~nm}$ & $7024544 \pm 15608$ & 0.22 & $2.00 \pm 0.06$ & 0.30 & $3136 \pm 95.16$ & 03 & $1.01 \pm 0.03$ & 0.30 \\
\hline & $226 \mathrm{~nm}$ & $6128799 \pm 10636$ & 0.18 & $2.01 \pm 0.08$ & 0.40 & $4268 \pm 101.3$ & 10 & $1.01 \pm 0.04$ & 0.40 \\
\hline & $228 \mathrm{~nm}$ & $7131156 \pm 12845$ & 0.18 & $2.00 \pm 0.004$ & 0.20 & $3334 \pm 88.58$ & 66 & $1.02 \pm 0.08$ & 0.78 \\
\hline
\end{tabular}

\footnotetext{
${ }^{*}$ Mean value of three determinations.
} 
2.3. Mobile Phase Preparation. Dissolved $0.5 \mathrm{~g}$ of potassium dihydrogen orthophosphate in $1000 \mathrm{~mL}$ of water and the $\mathrm{pH}$ was adjusted to 2.8 using $10 \%$ acetic acid. A $600 \mathrm{~mL}$ portion of this resulting buffer was mixed with $400 \mathrm{~mL}$ of acetonitrile, shaken well, and filtered using $0.22 \mu \mathrm{m}$ Nylon membrane filter. This solution was also used as diluent in all subsequent preparations of the sample.

2.4. Instrumental Parameters. The isocratic flow rate of mobile phase was maintained at $0.5 \mathrm{~mL} \mathrm{~min}^{-1}$. The column temperature was adjusted to $35^{\circ} \mathrm{C}$. The injection volume was $4.0 \mu \mathrm{L}$. The sample run was monitored at $226 \mathrm{~nm}$ and the run time was $5.0 \mathrm{~min}$. The retention time of the sample was observed at about $2.0 \mathrm{~min}$.

2.5. Stress Study. All stress decomposition studies were performed at an initial drug concentration of $200 \mu \mathrm{g} \mathrm{mL}^{-1}$ in mobile phase. Acid hydrolysis was performed in $1 \mathrm{M} \mathrm{HCl}$ at $80^{\circ} \mathrm{C}$ for $2 \mathrm{~h}$. The study in alkaline condition was carried out in $1 \mathrm{M} \mathrm{NaOH}$ at $80^{\circ} \mathrm{C}$ for $2 \mathrm{~h}$. For study in neutral condition, drug dissolved in water was heated at $80^{\circ} \mathrm{C}$ for $2 \mathrm{~h}$. Oxidative studies were carried out at $80^{\circ} \mathrm{C}$ in $5 \%$ hydrogen peroxide for $2 \mathrm{~h}$. For photolytic degradation studies, pure drug in solid state was exposed to 1.2 million lux hours in a photo stability chamber. Additionally, the drug powder was exposed to dry heat at $105^{\circ} \mathrm{C}$ for $3 \mathrm{~h}$. Samples were withdrawn at appropriate time, cooled, and neutralized by adding base or acid and subjected to UPLC analysis after suitable dilution.

2.6. Preparation of Stock Solution. Accurately weighed $100 \mathrm{mg}$ of pure TMH was dissolved in and diluted to mark in a $100 \mathrm{~mL}$ standard flask with the mobile phase.

\subsection{Procedures}

2.7.1. Procedure for Preparation of Calibration Curve. Working standard solutions containing $0.5-300 \mu \mathrm{g} \mathrm{mL}^{-1} \mathrm{TMH}$ were prepared by serial dilutions of aliquots of the stock solution. Aliquots of $4 \mu \mathrm{L}$ were injected (six injections) and eluted with the mobile phase under the reported chromatographic conditions. The average peak area versus the concentration of $\mathrm{TMH}$ in $\mu \mathrm{g} \mathrm{mL}^{-1}$ was plotted. Alternatively, the regression equation was derived using mean peak area-concentration data and the concentration of the unknown was computed from the regression equation.

2.7.2. Preparation of Tablet Extracts and Assay Procedure. Twenty Nobligan tablets (each containing $50 \mathrm{mg}$ TMH) were accurately weighed and ground into a fine powder. Powder equivalent to $20 \mathrm{mg}$ TMH was transferred into a $100 \mathrm{~mL}$ volumetric flask and $60 \mathrm{~mL}$ of the mobile phase was added. The mixture was sonicated for $20 \mathrm{~min}$ to achieve complete dissolution of $\mathrm{TMH}$, and the content was then diluted to volume with the mobile phase to yield a concentration of $200 \mu \mathrm{g} \mathrm{mL}^{-1} \mathrm{TMH}$, and filtered through a $0.22 \mu \mathrm{m}$ nylon membrane filter. The tablet extract was injected to the UPLC column. The same procedure was repeated with Meridol 50 (each tablet contained $50 \mathrm{mg}$ TMH) tablets.

\subsection{Procedure for Method Validation}

2.8.1. Accuracy and Precision. Six injections, of three different concentrations $\left(150,200\right.$, and $\left.250 \mu \mathrm{g} \mathrm{mL}^{-1}\right)$, were given on the same day and the values of relative standard deviation (RSD) were calculated to determine intraday precision. These studies were also repeated on different days to determine interday precision.

2.8.2. Limits of Detection (LOD) and Quantification (LOQ). Signal-to-noise $(\mathrm{S} / \mathrm{N})$ ratio method was adopted to obtain the limit of quantification (LOQ) and limit of detection (LOD). Series of dilutions of the TMH stock solution was made to attain LOQ and LOD in acceptable values. LOQ solution was injected six times $(n=6)$ and calculated the $\%$ RSD values for the obtained TMH peak area and retention time.

2.8.3. Linearity. Seven-point calibration curves were obtained in a concentration range from 0.5 to $300 \mu \mathrm{g} \mathrm{mL}$ $\left(0.5,50,100,150,200,250\right.$, and $300 \mu \mathrm{g} \mathrm{mL}^{-1}$ levels $)$ for $\mathrm{TMH}$; three independent determinations were performed at each concentration.

2.8.4. Robustness and Ruggedness. To determine the robustness of the method the experimental conditions were deliberately changed. The flow rate of the mobile phase

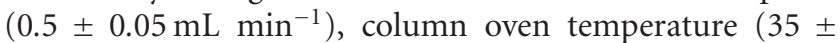
$\left.5^{\circ} \mathrm{C}\right)$, mobile phase composition $(66: 40,54: 40,60: 36$ and $60: 44$; buffer: solvent mixture v/v), and detection wavelength $(226 \pm 1 \mathrm{~nm})$ were the varied parameters. In each case, the \%RSD values were calculated for the obtained peak area and retention time. The number of theoretical plates and tailing factors were compared with those obtained under the optimized conditions. Three different columns of same dimensions were used for the analyses. The study was performed in a same day and three different days by three different analysts for three different concentrations of TMH (triplicate injections). The area obtained from each concentration was compared with that obtained under optimized conditions. The relative standard deviation values were evaluated for each concentration.

2.8.5. Solution Stability and Mobile Phase Stability. Stability of TMH solution was studied by injecting the sample into the chromatographic system at different time interval. The peak area was recorded in the time intervals of 0,12 , and 24 hrs and the RSD values were calculated. Freshly prepared solution was injected at the same time intervals for mobile phase stability $(0,12$, and 24 hours $)$ and RSD values of the peak areas were calculated.

\section{Results and Discussion}

3.1. Method Development. Different chromatographic conditions were experimented to achieve better efficiency of the chromatographic system. Parameters such as mobile phase composition, wavelength of detection, column, col- 


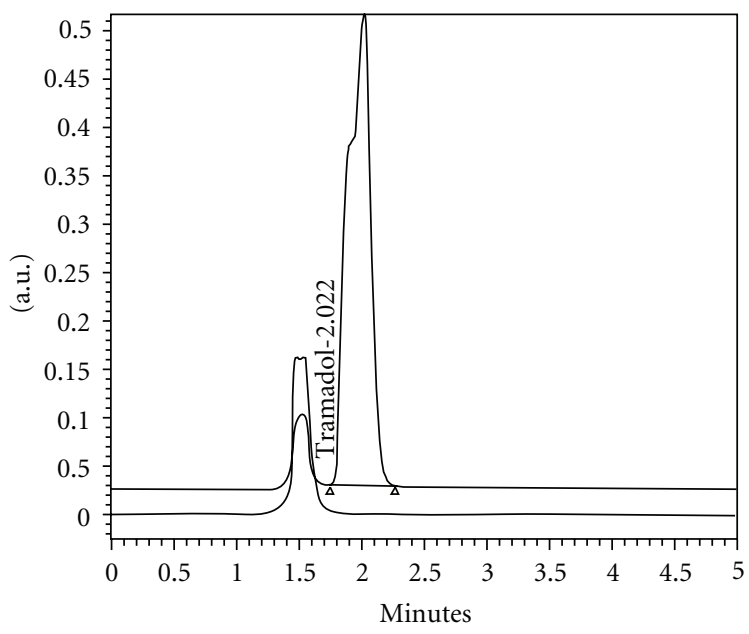

(a)

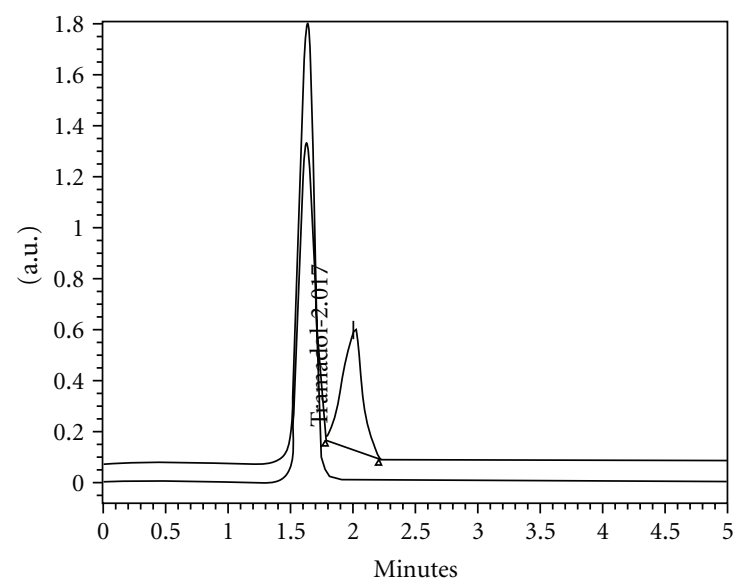

(c)

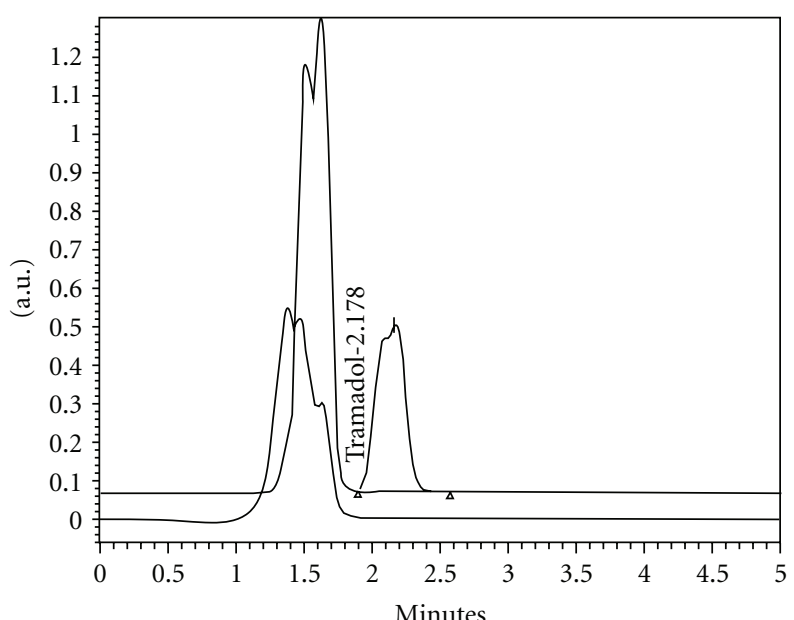

(b)

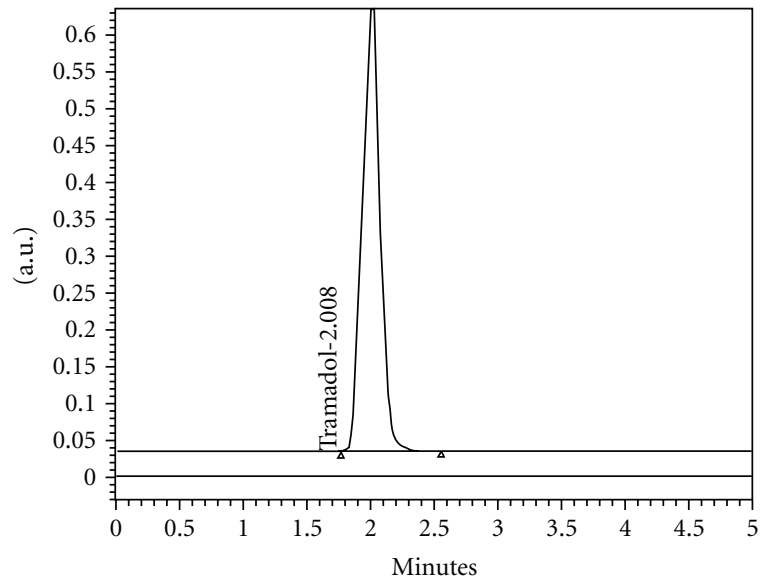

(d)

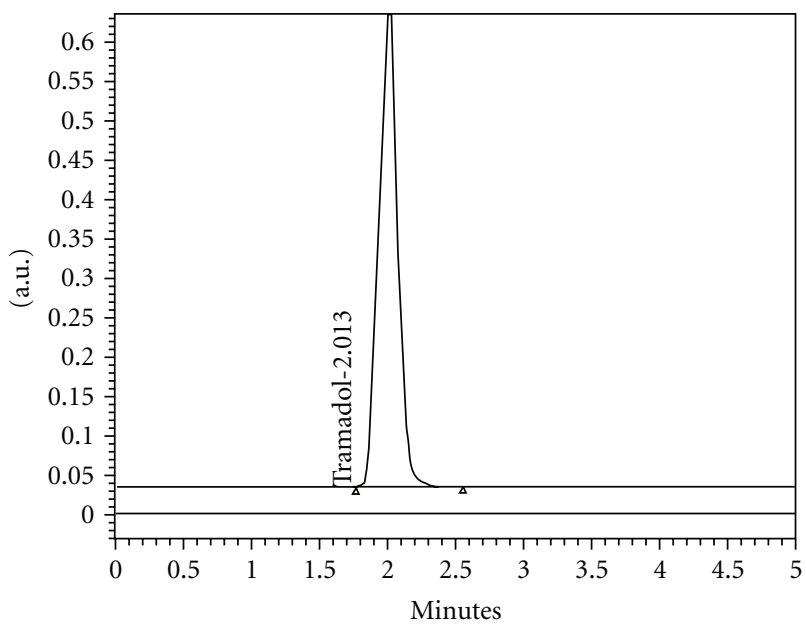

(e)

FIGURE 3: (a) Acid degradation, (b) base degradation, (c) oxidative degradation, (d) thermal degradation, and (e) photo degradation. 


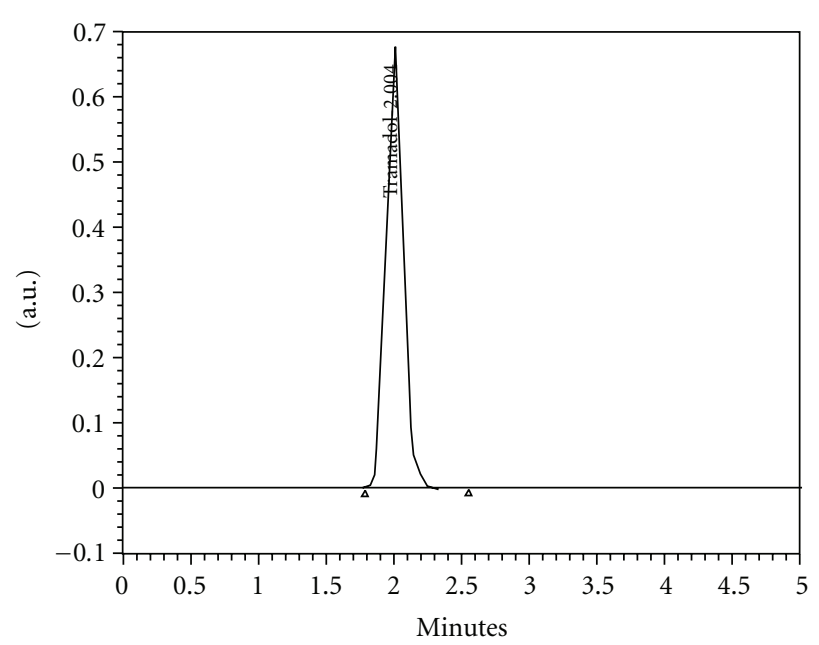

(a)

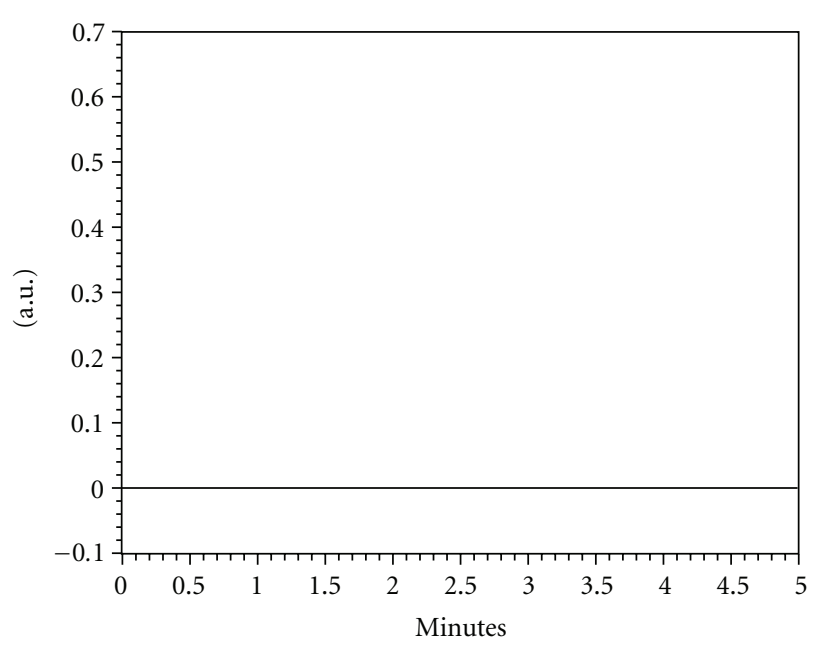

(b)

FIGURE 4: (a) Chromatogram of tablet extract, (b) chromatogram of placebo blank.

TABLE 5: Method ruggedness.

\begin{tabular}{lcccccccc}
\hline Variable & $\begin{array}{c}\text { Mean Peak area } \pm \\
\text { SD* }\end{array}$ & \%RSD & Mean Rt \pm SD $^{*}$ & \%RSD & $\begin{array}{c}\text { Mean } \\
\text { theoretical } \\
\text { plates } \pm \text { SD* }\end{array}$ & $\begin{array}{c}\text { \%RSD } \\
\text { factor } \pm \text { SD* }\end{array}$ & $\begin{array}{c}\text { Mean tailing } \\
\text { \%RSD }\end{array}$ \\
\hline Analyte $(n=3)$ & $6117724 \pm 12676$ & 0.21 & $2.005 \pm 0.03$ & 0.15 & $4076 \pm 9634$ & 2.36 & $1.03 \pm 0.003$ & 0.29 \\
\hline Column $(n=3)$ & $6123741 \pm 11896$ & 0.19 & $2.007 \pm 0.04$ & 0.20 & $4167 \pm 1034$ & 2.48 & $1.02 \pm 0.002$ & 0.20 \\
\hline
\end{tabular}

${ }^{*}$ Mean value of three determinations

umn temperature, $\mathrm{pH}$ of mobile phase, and diluents were optimized. Several proportions of buffer, and solvents (water, methanol and acetonitrile) were evaluated in order to obtain suitable composition of the mobile phase. Choice of retention time, tailing, theoretical plates, and run time were the major tasks while developing the method. Acquity $\mathrm{BEH}$ C18, $50 \mathrm{~mm} \times 2.1 \mathrm{~mm}, 1.7 \mu \mathrm{m}$ column used for the elution, but the peak eluted before 1.5 minutes with a tailing factor of 2. Experiment with Phenyl $100 \mathrm{~mm} \times 2.1 \mathrm{~mm}$, $2 \mu \mathrm{m}$ column ended with inconsistent retention time and peak fronting. Buffers like sodium dihydrogenothophosphate, dipotassium hydrogenorthophosphate, and disodium hydrogenorthophosphate did not yield desired results. Use of ion pair reagents also did not yield the expected peak. The following gradient conditions were experimented; the cycle time was set at $5 \mathrm{~min}, 10 \mathrm{~min}, 15 \mathrm{~min}$, or $20 \mathrm{~min}$, while the flow rate was set at either $300 \mu \mathrm{L} \mathrm{min}^{-1}$ or $600 \mu \mathrm{L} \mathrm{min}^{-1}$. Except for the $5 \mathrm{~min}$ cycle time, all gradients began with $100 \%$ buffer for $0.5 \mathrm{~min}$ and maintained for $1 \mathrm{~min}$ at the end of each cycle for equilibration. For a cycle time of 5 min, conditions started with $100 \%$ buffer for $0.5 \mathrm{~min}$, then proceeded with a linear gradient to $100 \%$ acetonitrile for $3 \mathrm{~min}$, then returned to initial conditions and maintained upto $5 \mathrm{~min}$. The gradient method was successful in good peak shape of drug and all chromophoric degradation products. The effect of different elution gradients was assessed under either linear (described above) curve or step gradient which was controlled by the Waters Empower- 2 software. At $60: 40$ ratio of the mobile phase in the linear gradient program, a perfect peak was eluted. Thus the mobile phase ratio was fixed at 60:40 (buffer: solvent) in an isocratic mobile phase flow rate. The typical chromatograms obtained for blank and pure TMH from final UPLC conditions are depicted in Figure 2.

3.2. Stability Studies. All forced degradation studies were analyzed at $200 \mu \mathrm{g} \mathrm{mL}^{-1}$ concentration level. The observation was made based on the peak area of the respective sample. TMH was found to be more stable under photolytic (1.2 million lux hours), thermal $\left(105^{\circ} \mathrm{C}\right.$ for 3 hours) in solid state, and hydrolytic (aqueous, $80^{\circ} \mathrm{C}$ for 2 hours) stress conditions. The drug was found to be sensitive to acid and alkaline stress conditions resulting in the decomposition to the extent of 44.3 and $34.6 \%$, respectively. Less degradation occurred under oxidative stress conditions with percent decomposition being only $2.1 \%$. The chromatograms obtained for $\mathrm{TMH}$ after subjecting to degradation are presented in Figure 3. Assay study was carried out by the comparison with the peak area of $\mathrm{TMH}$ sample without degradation.

3.3. Validation of the Method. The described method for the assay of TMH has been validated as per the current ICH Q2 (R1). 
TABLE 6: Results of determination of TMH in tablet and statistical comparison with the reference method.

\begin{tabular}{lccccc}
\hline $\begin{array}{l}\text { Formulation } \\
\text { brand name }\end{array}$ & $\begin{array}{c}\text { Nominal } \\
\text { amount, mg }\end{array}$ & Reference method & Proposed method & t-value & F-value \\
\hline Nobligan $^{\mathrm{a}}$ & 50.0 & $101.6 \pm 1.64$ & $100.1 \pm 0.65$ & 1.94 & 6.36 \\
Meridol $^{\mathrm{b}}$ & 50.0 & $101.8 \pm 1.36$ & $99.98 \pm 0.86$ & 2.52 & 2.50 \\
\hline
\end{tabular}

${ }^{a}$ Marketed by Piramal HC Ltd, Mumbai, India.

${ }^{b}$ Unimarc India Ltd, Mumbai, India.

${ }^{*}$ Mean value of five determinations. Tabulated $t$-value at $95 \%$ confidence level is 2.78 ; Tabulated $F$-value at $95 \%$ confidence level is 6.39 .

TABLE 7: Results of recovery study by standard addition method.

\begin{tabular}{|c|c|c|c|c|}
\hline Tablet studied & $\mathrm{TMH}$ in tablet, $\mu \mathrm{g} \mathrm{mL}^{-1}$ & Pure $\mathrm{TMH}$ added, $\mu \mathrm{g} \mathrm{mL}^{-1}$ & Total found, $\mu \mathrm{g} \mathrm{mL}^{-1}$ & $\begin{array}{c}\text { Pure TMH } \\
\text { recovered* } \\
(\% \mathrm{TMH} \pm \mathrm{SD})\end{array}$ \\
\hline \multirow{3}{*}{ Nobligan } & 100.1 & 50.0 & 150.50 & $100.8 \pm 1.98$ \\
\hline & 100.1 & 100.0 & 200.51 & $100.4 \pm 0.98$ \\
\hline & 100.1 & 150.0 & 249.38 & $99.69 \pm 0.97$ \\
\hline \multirow{3}{*}{ Meridol } & 99.98 & 50.0 & 150.63 & $101.3 \pm 0.80$ \\
\hline & 99.98 & 100.0 & 199.45 & $99.47 \pm 0.57$ \\
\hline & 99.98 & 150.0 & 249.26 & $99.52 \pm 0.34$ \\
\hline
\end{tabular}

${ }^{*}$ Mean value of five determinations.

3.3.1. Analytical Parameters. A calibration curve was obtained for TMH from $0.5 \%$ to $150 \%$ of its stock solution. A linear correlation was obtained between the peak area and the concentration in the range of $0.5-300 \mu \mathrm{g} \mathrm{mL}^{-1} \mathrm{TMH}$ from which the linear regression equation was computed and found to be

$$
y=30.620 x+19.330, \quad r^{2}=0.9999,
$$

where $y$ is the mean peak area, $x$ is the concentration of TMH in $\mu \mathrm{g} \mathrm{mL}^{-1}$, and $r$ is the correlation coefficient. The LOD and LOQ values, slope $(m), y$-intercept $(a)$, and their standard deviations are evaluated and presented in Table 1. These results confirm the linear relation between concentration of $\mathrm{TMH}$ and the peak areas as well as the sensitivity of the method.

3.3.2. Accuracy and Precision. The percent relative error which is an indicator of accuracy is $\leq 1.0$ and is indicative of high accuracy. The calculated percent relative standard deviation (\%RSD) can be considered to be satisfactory. The peak-area-based and retention-time-based RSD values were $<1 \%$. The results obtained for the evaluation of accuracy and precision of the method are compiled in Tables 2 and 3.

3.3.3. Robustness and Ruggedness. The robustness of an analytical procedure is a measure of its capacity to remain unaffected by small, but deliberate variations in method parameters, and provides an indication of its reliability during normal usage. At the deliberate varied chromatographic conditions (flow rate, temperature, and mobile phase composition), the analyte peak \%RSD, tailing factor, and theoretical plates remained closer to the actual values. The RSD values ranged from 0.1 to $1.3 \%$ resumes the robustness of the proposed method. In method ruggedness, different columns (same lot), at different day by different analysts were performed. The results are summarized in Tables 4 and 5 .

3.3.4. Stability of the Solution. At the specified time interval, $\%$ RSD for the peak area obtained from drug solution stability and mobile phase stability were within $1 \%$. This shows no significant change in the elution of the peak and its system suitability criteria (\%RSD, tailing factor, and theoretical plates). The results also confirmed that the standard solution of drug and mobile phase were stable at least for 24 hours during the assay performance.

3.3.5. Selectivity. Selectivity of the method was evaluated by injecting the mobile phase, placebo blank, pure drug solution, and tablet extract. No peaks were observed for mobile phase and placebo blank and no extra peaks were observed for tablet extracts (Figures 4(a) and 4(b)).

3.3.6. Application to Tablet. A $200 \mu \mathrm{g} \mathrm{mL}^{-1}$ solution of tablets was prepared as per "preparation of tablet extracts and assay procedure" and injected in triplicate to the UPLC system. The mean peak area of the tablet extract for this concentration was found to be equivalent to that of pure drug solution of the same concentration and the results were compared with those of a reference method [4]. The accuracy and precision of the proposed method was further evaluated by applying Student's $t$-test and variance ratio $F$-test, respectively. The $t$ - and $F$-values at $95 \%$ confidence level did not exceed the tabulated values and this further confirms that there is no significant difference between the reference and proposed methods with respect to accuracy and precision. Table 6 illustrates the results obtained from this study.

3.3.7. Recovery Study. A standard addition procedure was followed to further evaluate the accuracy of the method. 
The solutions were prepared by spiking preanalyzed tablet with pure drug at three different levels and injected to chromatographic column. The recovery of the known amount of added analyte was computed. The percentage recovery of TMH from pharmaceutical dosage forms ranged from 99.4 to $101.34 \%$. The results presented in Table 7 reveal good accuracy of the proposed method.

\section{Conclusions}

In this work, a stability indicating UPLC method was developed and validated for the determination of tramadol hydrochloride (TMH) in bulk and tablet dosage forms. The results of stress testing undertaken according to International Conference on Harmonization guidelines reveal that the method is selective and stability indicating which shows the applicability of the method for quality control. TMH was found to be more stable under thermolytic and photolytic stress conditions in the solid state rather than in acidic, basic, or aqueous stress condition in solution.

\section{Acknowledgments}

The authors are thankful to the University of Mysore for providing the permission and facilities to do research work. The authors do not have any conflict of interests. Three of the authors (K. B. Vinay, C. M. Xavier, and P. J. Ramesh) are grateful to Jubilant Life Sciences, Nanjangud, Mysore, for permission to pursue Ph.D. degree programme.

\section{References}

[1] G. Grosa, E. D. Grosso, R. Russo, and G. Allegrone, "Simultaneous, stability indicating, HPLC-DAD determination of guaifenesin and methyl and propyl-parabens in cough syrup," Journal of Pharmaceutical and Biomedical Analysis, vol. 41, no. 3, pp. 798-803, 2006.

[2] K. Budd and R. Langford, "Tramadol revisited," British Journal of Anaesthesia, vol. 82, no. 4, pp. 493-495, 1999.

[3] P. Dayer, J. Desmeules, and L. Collart, "The pharmacology of tramadol," Drugs, vol. 53, no. 2, pp. 18-24, 1997.

[4] European Pharmacopoeia, Strasbourg, Council of Europe, vol. 6.0, pp.3104-3105, 2008.

[5] F. W. Mang, W. Liu, and J. N. Y. Ang, "Ultra-violet spectrophotometric analysis of tramadol hydrochloride injections," Yaowu Fenxi Zazhi, vol. 14, article 42, 1994.

[6] A. Küçük and Y. Kadioğlu, "Determination of tramadol hydrochloride in ampoule dosage forms by using UV spectrophotometric and HPLC-DAD methods in methanol and water media," Il Farmaco, vol. 60, no. 2, pp. 163-169, 2005.

[7] W. F. Kartinasari, T. Palupi, and G. Indrayanto, "HPLC determination and validation of tramadol hydrochloride in capsules," Journal of Liquid Chromatography and Related Technologies, vol. 27, no. 4, pp. 737-744, 2004.

[8] I. Y. Zaghloul and M. A. Radwan, "High performance liquid chromatographic determination of tramadol in pharmaceutical dosage forms," Journal of Liquid Chromatography and Related Technologies, vol. 20, no. 5, pp. 779-787, 1997.

[9] Y. L. Zhong, "Determination of the content of tramadol hydrochloride sustained-release tablets," Yaowu Fenxi Zazhi, vol. 17, pp. 279-280, 1997.
[10] J. Krzek and M. Starek, "Quality assessment for tramadol in pharmaceutical preparations with thin layer chromatography and densitometry," Biomedical Chromatography, vol. 18, no. 8, pp. 589-599, 2004.

[11] M. Pospíšilová, M. Polášek, and V. Jokl, "Determination of tramadol in various dosage forms by capillary isotachophoresis," Journal of Pharmaceutical and Biomedical Analysis, vol. 18, no. 4-5, pp. 777-783, 1998.

[12] J. K. Zhang, J. G. Li, and Y. F. Tu, "Flow injection chemiluminescence determination of tramadol hydrochloride," Fenxi Kexue Xuebao, vol. 25, pp. 173-176, 2009.

[13] F. Ghorbani-Bidkorbeh, S. Shahrokhian, A. Mohammadi, and R. Dinarvand, "Simultaneous voltammetric determination of tramadol and acetaminophen using carbon nanoparticles modified glassy carbon electrode," Electrochimica Acta, vol. 55, no. 8, pp. 2752-2759, 2010.

[14] E. M. P. J. Garrido, J. M. P. J. Garrido, F. Borges, and C. Delerue-Matos, "Development of electrochemical methods for determination of tramadol-analytical application to pharmaceutical dosage forms," Journal of Pharmaceutical and Biomedical Analysis, vol. 32, no. 4-5, pp. 975-981, 2003.

[15] P. Norouzi, R. Dinarvand, M. R. Ganjali, and A. S. E. Meibodi, "Application of adsorptive stripping voltammetry for the nano-level detection of tramadol in biological fluids and tablets using fast fourier transform continuous cyclic voltammetry at an au microelectrode in a flowing system," Analytical Letters, vol. 40, no. 11, pp. 2252-2270, 2007.

[16] M. R. Ganjali, Z. Memari, F. Faridbod, R. Dinarvand, and P. Norouzi, "Sm${ }^{3+}$ potentiometric membrane sensor as a probe for determination of some pharmaceutics," Electroanalysis, vol. 20, no. 24, pp. 2663-2670, 2008.

[17] Y. J. Wu, J. Shi, J. H. Zhang, K. L. Zhao, and Z. P. Zhang, "Preparation and application of an ion-selective electrode by tramadol hydrochloride," Fenxi shiyanshi, vol. 24, pp. 49-51, 2005.

[18] C. L. Huang, R. Xiu, Q. X. Dong, X. Z. Chen, and H. Q. You, "Preparation of a PVC membrane tramadol ionselective electrode based on gel quinhydrone internal reference electrode," Fenxi Ceshi Xuebao, vol. 24, pp. 35-38, 2005.

[19] C. L. Huang, R. Xiu, Z. Y. Liu, Y. C. Li, and C. J. Meng, "Preparation and application of a doubly coated membrane tramadol ion-selective electrode based on $\mathrm{Ag} / \mathrm{AgCl}$ wire," Fenxi Kexue Xuebao, vol. 21, pp. 48-50, 2005.

[20] M. Wang, Y. Long, D. Li, W. Zhou, G. Zhao, and Z. Zhang, "Preparation of polyvinyl chloride membrane ofloxacin and tramadol selective electrode and its application," Fenxi Huàxué, vol. 25, no. 4, pp. 450-451, 1997.

[21] H. Hopkala, G. Misztal, and A. Wieczorek, "Tramadol selective PVC membrane electrodes and their analytical application," Pharmazie, vol. 53, no. 12, pp. 869-871, 1998.

[22] J. Yue, Q. Yu, D. Li, G. Zhao, W. Shi, and L. An, "Preparation and application of polyvinyl chloride membrane-tramadol selective electrode," Fenxi Huàxué, vol. 28, no. 1, pp. 84-86, 2000.

[23] R. J. Sadhana and P. D. Trivedi, "Assay of tramadol hydrochloride by spectrophotometry," Indian Drugs, vol. 38, no. 2, pp. 100-101, 2001.

[24] H. E. Abdellatef, M. M. El-Henawee, H. M. El-Sayed, and M. M. Ayad, "Spectrophotometric and spectrofluorimetric methods for analysis of tramadol, acebutolol and dothiepin in pharmaceutical preparations," Spectrochimica Acta-Part A, vol. 65, no. 5, pp. 1087-1092, 2006.

[25] H. E. Abdellatef, "Kinetic spectrophotometric determination of tramadol hydrochloride in pharmaceutical formulation," 
Journal of Pharmaceutical and Biomedical Analysis, vol. 29, no. 5, pp. 835-842, 2002.

[26] K. B. Vinay, H. D. Revanasiddappa, N. Rajendraprasad et al., "Rapid titrimetric and spectrophotometric assay of tramadol in bulk drug and in formulation using N-bromosuccinimide and methyl orange as reagents," Thai Journal of Pharmaceutical Sciences, vol. 35, no. 1, pp. 8-17, 2011.

[27] K. B. Vinay, H. D. Revanasiddappa, M. R. Divya, N. Rajendra Prasad, and K. Basavaiah, "Sensitive spectrophotometric assay of tramadol in pharmaceuticals using N-bromosuccinimide and indigocaramine," Proceedings of Indian National Academy Science, vol. 76, no. 2, pp. 71-79, 2010.

[28] K. B. Vinay, H. D. Revanasiddappa, N. Rajendraprasad, P. J. Ramesh, Xavier Cijo M., and K. Basavaiah, "Use of two sulfonthalein dyes in the extraction-free spectrophotometric assay of tramadol in dosage forms and in spiked human urine based on ion-pair reaction," Drug Testing and Analysis, vol. 4, no. 2, pp. 116-122, 2012.

[29] K. Basavaiah, M. R. Divya, N. Rajendra Prasad, P. J. Ramesh, C. M. Xavier, and K. B. Vinay, "Determination of tramadol $\mathrm{HCl}$ and its preparations by acid-base titrimetry in non aqueous medium," Journal of Preclinical Clinical Research, vol. 4, no. 1, pp. 19-23, 2010.

[30] A. B. Thomas, N. G. Dumbre, R. K. Nanda, L. P. Kothapalli, A. A. Chaudhari, and A. D. Deshpande, "Simultaneous determination of tramadol and ibuprofen in pharmaceutical preparations by first order derivative spectrophotometric and LC methods," Chromatographia, vol. 68, no. 9-10, pp. 843-847, 2008.

[31] A. Satmeron-Garcia, E. Lopez-lopez, E. Roman, J. Carbeza, N. Navas, and L.-F. Capitan-Vally, "Development of an LCDAD method for analysis of dexketoprafen, tramadol and haloperidol, Study of the stability of mixtures for patient controlled analgesia," Chromatographia, vol. 68, no. 9-10, pp. 762-772, 2008.

[32] P. K. Kachhadia, A. S. Doshi, V. R. Ram, and H. S. Joshi, "Validated LC method for simultaneous analysis of tramadol hydrochloride and aceclofenac in a commercial tablet," Chromatographia, vol. 68, no. 11-12, pp. 997-1001, 2008.

[33] K. Karunakaran, G. Navaneethan, and K. P. Elango, "Development and validation of a stability-indicating RP-HPLC method for simultaneous determination of paracetamol, tramadol HCL and domperidone in a combined dosage form," Tropical Journal of Pharmaceutical Research, vol. 11, pp. 99106, 2012.

[34] S. Singh, B. Singh, R. Bahuguna, L. Wadhwa, and R. Saxena, "Stress degradation studies on ezetimibe and development of a validated stability-indicating HPLC assay," Journal of Pharmaceutical and Biomedical Analysis, vol. 41, no. 3, pp. 1037-1040, 2006.

[35] A. Mohammadi, I. Haririan, N. Rezanour, L. Ghiasi, and R. B. Walker, "A stability-indicating high performance liquid chromatographic assay for the determination of orlistat in capsules," Journal of Chromatography A, vol. 1116, no. 1-2, pp. 153-157, 2006.

[36] I. Ivana, Z. Ljiljana, and Z. Mira, "A stability indicating assay method for cefuroxime axetil and its application to analysis of tablets exposed to accelerated stability test conditions," Journal of Chromatography A, vol. 1119, no. 1-2, pp. 209-215, 2006.

[37] K. Basavaiah, N. Rajendraprasad, M. X. Cijo, K. B. Vinay, and P. J. Ramesh, "Development and validation of stability indicating spectrophotometric methods for determination of oxcarbazepine in pharmaceuticals," Journal of Scientific and Industrial Research, vol. 70, no. 5, pp. 346-351, 2011.
[38] International Conference on Harmonization Q1A (R2), “ Stability testing of new drug substances and products. International conference on harmonization," IFPMA, Geneva, Swziterland, 2006.

[39] A. Mohammadi, S. Nojavan, M. Rouini, and A. R. Fakhari, "Stability evaluation of tramadol enantiomers using a chiral stability-indicating capillary electrophoresis method and its application to pharmaceutical analysis," Journal of Separation Science, vol. 34, no. 13, pp. 1613-1620, 2011.

[40] V. D. Gupta, "Chemical stability of tramadol hydrochloride injection," International Journal of Pharmaceutical Compounding, vol. 12, no. 2, pp. 161-162, 2008.

[41] L. Nováková, L. Matysová, and P. Solich, "Advantages of application of UPLC in pharmaceutical analysis," Talanta, vol. 68, no. 3, pp. 908-918, 2006.

[42] R. Verplaetse and J. Tytgat, "Development and validation of a sensitive UPLC-MS/MS method for the analysis of narcotic analgesics in urine and whole blood in forensic context," Forensic Science International, 2011.

[43] B. Kasprzyk-Hordern, R. M. Dinsdale, and A. J. Guwy, "Multiresidue method for the determination of basic/neutral pharmaceuticals and illicit drugs in surface water by solid-phase extraction and ultra performance liquid chromatographypositive electrospray ionisation tandem mass spectrometry," Journal of Chromatography A, vol. 1161, no. 1-2, pp. 132-145, 2007.

[44] N. Badawi, K. W. Simonsen, A. Steentoft, I. M. Bernhoft, and K. Linnet, "Simultaneous screening and quantification of 29 drugs of abuse in oral fluid by solid-phase extraction and ultraperformance LC-MS/MS," Clinical Chemistry, vol. 55, no. 11, pp. 2004-2018, 2009.

[45] D. R. Baker and B. Kasprzyk-Hordern, "Multi-residue analysis of drugs of abuse in wastewater and surface water by solid-phase extraction and liquid chromatography-positive electrospray ionisation tandem mass spectrometry," Journal of Chromatography A, vol. 1218, no. 12, pp. 1620-1631, 2011. 


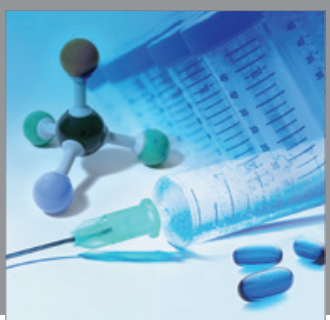

International Journal of

Medicinal Chemistry

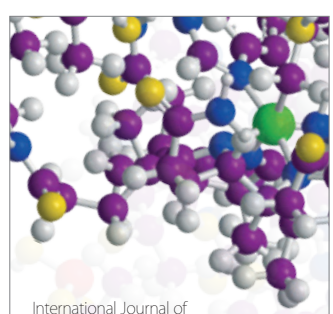

Carbohydrate Chemistry

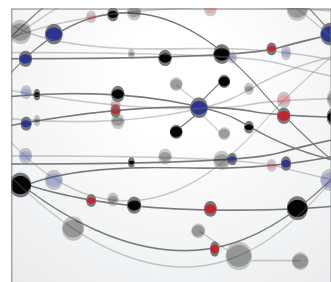

The Scientific World Journal
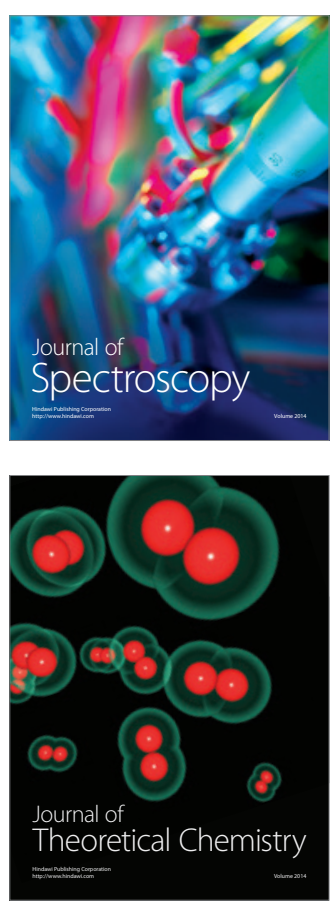
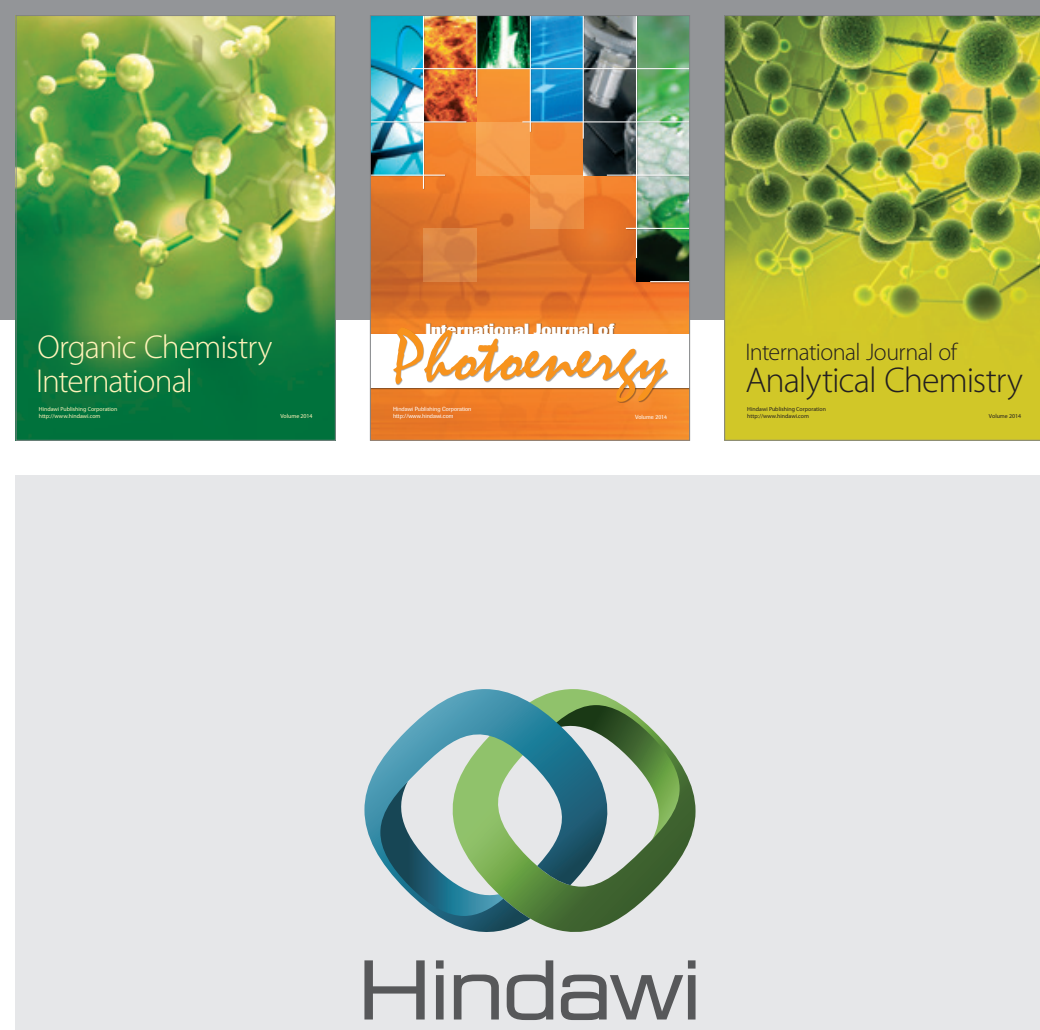

Submit your manuscripts at

http://www.hindawi.com
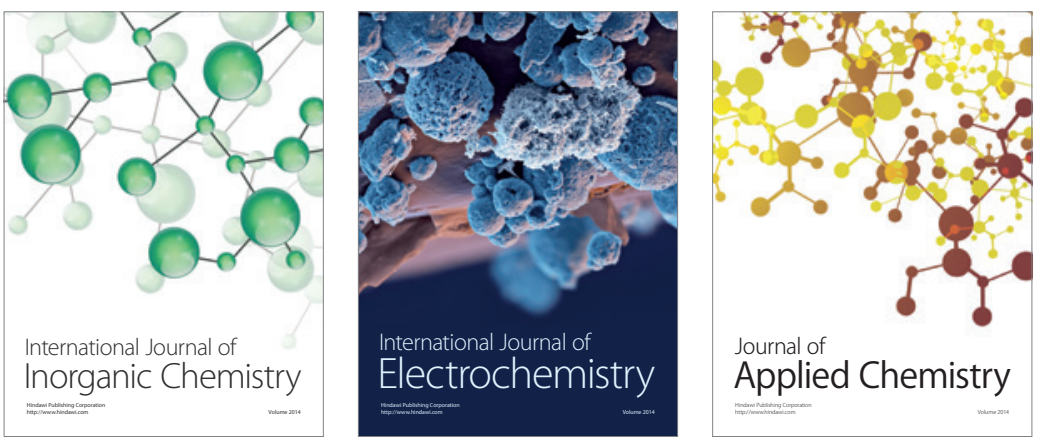

Journal of

Applied Chemistry
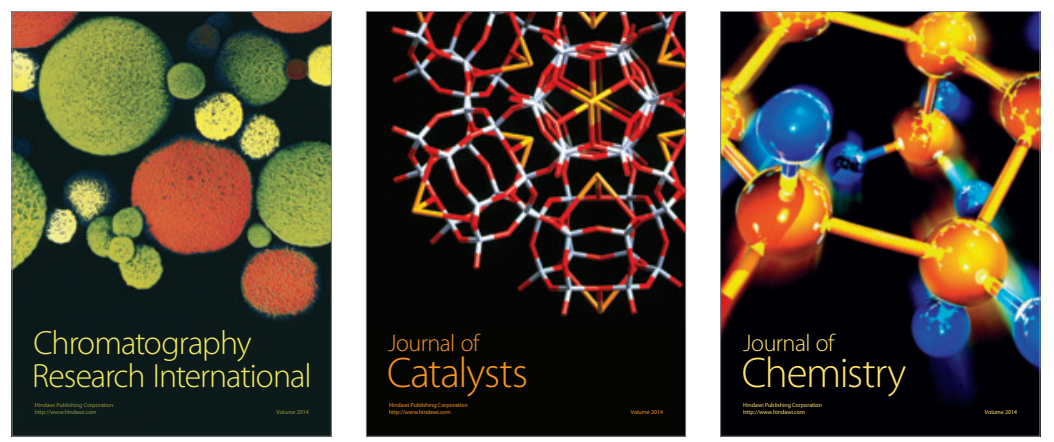
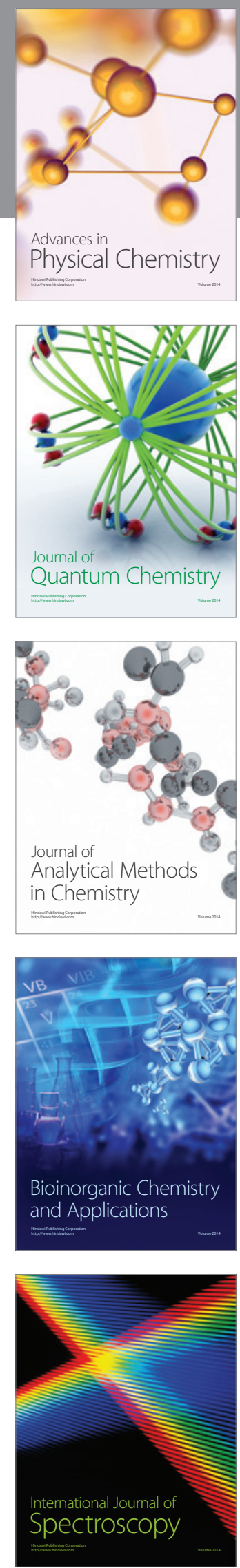